DOI 10.37882/2500-3682.2020.05.09

\title{
ПОЗИТИВНЫЕ И НЕГАТИВНЫЕ СТОРОНЫ ФЕНОМЕНА «УХОДА В СВОИ МЫСЛИ»
}

\section{THE POSITIVE AND NEGATIVE ASPECTS OF THE PHENOMENON OF «MIND-WANDERING»}

\section{E. Matveeva}

Summary: The concept of "mind-wandering» is a special state of consciousness, which is associated with a decrease in attention from the perception of external information and its concentration on the processes occurring inside. This phenomenon is characterized by spontaneity and involuntaryness in terms of filling. In this state, thoughts are generated in the human mind that focus on important tasks for a person, but, on the other hand, are negatively related to the processing of external information, as a result of which errors may occur in current activities. Such a personality trait as dreaminess is inextricably linked with the concept of «mind-wandering».

The motivational significance of «mind-wandering» lies not only in the personal significance of the content of thoughts. "mind-wandering» is directly related to other mental concepts:

- reflection

- metacognition (metacognition),

- mindfulness».

Today, researchers agree that «mind-wandering» in daily activities is a widespread condition. When performing current activities, it can be the reason for making mistakes due to carelessness. But on the other hand, it is precisely "withdrawal into one's thoughts" that acts as a useful tool in the long run, starts evaluating experience from the past, planning new activities and incubating creative solutions.

This article presents an approach that allows you to distinguish between the above concepts and consider the distinctive features of «mindwandering» on the basis of negative and positive impact on current activities. Of particular note is the study of cognitive control in initiating and stopping episodes of «mind-wandering».

Keywords: consciousness, attention, "mind-wandering», daydreaming, reflection, metacognition, meta-consciousness, mindfulness.
Матвеева Евгения Юрьевна

Аспирант, Новосибирский государственный университет экономики и управления epoteruha@mail.ru

Аннотация: Понятие «ухода в свои мысли» (англ. термин «mindwandering») - представляет собой особое состояние сознания, которое сопряжено со снижением внимания от восприятия внешней информации и его концентрация на процессах, происходящих внутри. Этому феномену свойственна спонтанность и непроизвольностью в части наполнения. В этом состоянии в сознании человека рождаются мысли, которые сосредотачиваются вокруг важных для человека задач, но, с другой стороны, негативно соотносятся с обработкой внешней информации, в результате чего возможно возникновение ошибок в текущей деятельности. Такая черта личности как мечтательность неразрывно связана с понятием «ухода в свои мысли».

Мотивационная значимость «ухода в свои мысли» заключается не только в личностной значимости содержания мыслей. «Уход в Свои мысли» напрямую связан с другими психическими понятиями:

- рефлексия,

- метапознание (метасознание),

- mindfulness».

Сегодня исследователи сходятся во мнении, что «уход в свои мысли» в ежедневной деятельности - широко распространенное состояние. При выполнении текущей деятельности оно может быть причиной допущения ошибок из-за невнимательности. Но, с другой стороны, именно «уход в свои мысли» выступает в роли полезного инструмента в долгосрочной перспективе, запускает оценку опыта из прошлого, планирование новой деятельности и инкубацию творческих решений.

В данной статье представлен подход, который позволяет разграничить вышеупомянутые понятия и рассмотреть отличительные черты «ухода в свои мысли» по признаку негативного и позитивного влияния на текущую деятельность. Особое внимание заслуживает изучение когнитивного контроля в инициации и остановке эпизодов «ухода в свои мысли».

Ключевые слова: сознание, внимание, «уход в свои мысли», мечтательность, рефлексия, метапознание, метасознание, полнота осознания.
$\Phi$ еномен «ухода в свои мысли» был определен ведущими исследователями как режим работы нашего мозга по умолчанию, и это было связано с дезадаптивными последствиями для здоровья. Несмотря на повсеместное распространение данного понятия, мало что известно о его функциональности. Исследователями было выдвинуто предположение, что уход в свои мысли играет жизненно важную роль в здоровом познании, и недавние работы авторов предлагают адаптивные функции, которые выполняет этот феномен. Например, «уход в свои мысли» объединяет прошлый и настоящий опыт для целей будущего планирования и моделирования. Согласно этой гипотезе, опыт ухода в свои мысли часто ориентирован на будущее и на разрешение личных целей. Вдохновение - это еще одна функция, которая может быть интуитивно связана с данным термином, особенно с учетом хорошо известных преимуществ «инкубационного периода» для творческих мыслей. «Уход в себя» способствует творческому решению проблем. Растущее число исследований указывает на то, что способность мысленно избегать ограничений настоящего времени позволяет управлять личными целями. В со- 
ответствии с этой точкой зрения, изучаемое понятие позволяет познанию быть посвященным рассмотрению личных целей, которые выходят за рамки текущего момента, становясь актуальными для принятия решений, выгодных в долгосрочной перспективе. Среди других функций «уход в свои мысли» может служить механизмом обучения и обобщения, расширяя ассоциативные способности мозга, подобно тому, что происходит, когда человек спит.

С другой стороны, «уход в свои мысли», как это ни парадоксально, связан с неконструктивными последствиями с точки зрения снижения внимания и результативности при выполнении задач, требующих значительной контролируемой обработки. Ряд исследований связывал изучаемый феномен с плохой работой в задачах с постоянным вниманием, таких как задачи по бдительности или чтением. Во время чтения «уход в себя» приводит к замедлению процесса, средней продолжительности фиксации, что негативно влияет на понимание сложных текстов. Если посмотреть на последствия шире, то «уход в свои мысли» может привести к дорожно-транспортным происшествиям и медицинской халатности. Если последнее покажется нелогичным, то следует учитывать, что рассматриваемое понятие влияет на более высокие процессы, такие как принятие решений. Что касается воздействия на здоровье и благополучие, то мнения исследователей разделились: одни убеждены только в негативных последствиях «ухода в свои мысли», в то время как другие исследования поддерживают противоположную точку зрения. Кроме того, «уход в себя» связывают с возникновением психопатологических расстройств, таких как дисфория и синдром дефицита внимания с гиперактивностью. Что касается психофизиологической реактивности, исследователи обнаружили ускорение сердечного ритма (ЧСС) в периоды «ухода в свои мысли» при выполнении задачи постоянного внимания. Кроме того, прослеживается положительная корреляция между физиологическим возбуждением (ЧСС) и частотой эпизодов «ухода в свои мысли» во время задачи семантического кодирования.

В основе понятия «ухода в свои мысли» стоит способность мозга вырабатывать и поддерживать в сознании внутренний поток информации, не имеющий взаимосвязи со стимулом извне. Исследование этого феномена несет огромную значимость для понимания состояний сознания, где когнитивные процессы не связаны с восприятием действительности в настоящий момент.

Внимание - ключевая составляющая ежедневной деятельности людей. Согласно П.Я. Гальперину (1998), данное понятие означает самостоятельный активный психический процесс, целенаправленную деятельность контроля, которая подвержена действию внешних и внутренних факторов (помех). Один из главных факторов, встраивающихся в механизм внимания и негативно влияющих на его продуктивность в деятельности человека выступает «уход в свои мысли». Уже на протяжении длительного времени исследователи различных областей психологии занимаются изучением спонтанного процесса мышления, в котором находят отражение характеристики личности, в частности:

- представление о себе и о других,

- установки,

- скрытые мотивы поведения;

Такая черта как мечтательность тесно взаимосвязана с «уходом в свои мысли». Мечты, фантазии, галлюцинаторные образы появляются при сенсорной депривации, клинической патологии и состоянии сниженного бодрствования. Но важно отметить, что мечтательность не характеризуется только лишь данными состояниями. Предрасположенность к мечтательности у здорового человека отражается в частоте случаев «ухода в свои мысли». Данное состояние сознания возникает во время различных видов активностей в течение всего суточного этапа бодрствования. Возникновение случаев «ухода в свои мысли» обусловлено влиянием следующих факторов:

- монотонность и степень автоматизации действий

- психофизиологическое состояние (например, тревога перед предстоящей встречей увеличивает количество случаев «ухода в свои мысли»).

Эксперименты по изучению феноменов мечтательности и «ухода в свои мысли» проводятся с середины XX в. Дж.Л. Сингером и Дж.С. Антробусом. Сегодня для исследования данных понятий используется комплексный подход с акцентом на поведенческие показателей при решении задач, где необходимо сосредоточение внимания к стимулам извне (например, задача «устойчивого внимания к ответу» Дж. Смолвуда и Дж.У. Скулера). Взаимосвязь «ухода в свои мысли» с такими понятиями как mindfulness и рефлексия еще недостаточно исследована на сегодняшний день.

Под понятием «уход в свои мысли» имеется в виду состояние сознания, занимающее около $50 \%$ длительности этапа бодрствования. Оно связано с отстранением внимания от восприятия информации из внешнего мира. Данному состоянию свойственна спонтанность, а также непроизвольность. Уровень рациональности мышления случае «ухода в свои мысли» невелик, но тем не менее выше, чем в момент пребывания в состоянии сна. Несмотря на то, что «уход в свои мысли» происходит в основном непроизвольно, в отдельных случаях он возникает по инициативе человека, в частности при утрате интереса к происходящему вокруг событиям.

Если обобщить ранее изученные характеристики понятия «уход в свои мысли», то они выглядят следующим 
образом:

- отсоединение внимания (decoupling) от внешней деятельности, концентрация на волне внутренней информации;

- отсутствие контроля над содержанием сознания;

- получение информации из эпизодической памяти;

- мыслительный процесс сосредотачивается на личных целях.

Руминации и инкубация творческих решений являются двумя яркими примерами проявления феномена «ухода в свои мысли».

Руминации (навязчивые повторяющиеся мысли) зачастую связаны депрессией или высоким уровнем тревожности. Л.Л. Мартин и А. Тессер описывали повторяющиеся мысли как составляющую сознания. Идея теории стиля реагирования Е.Р. Уоткинса заключается в том, что так называемая умственная «жвачка» возникает В ответ на депрессивное настроение и является постоянной характеристикой человека. В состоянии стресса руминации могут являться причиной застойности данного состояния и требуют психотерапевтического вмешательства. Если взглянуть на это понятие под другим углом, феномен «ухода в свои мысли» может создавать и поддерживать инкубацию креативных решений (например, «творческая рассеянность»).

Основной негативной стороной «ухода в свои мысли» является то, что человек в этом состоянии имеет склонность к невнимательности при выполнении задач, кроме того, снижается способность понимания прочитанного текста. Дж.С. МакВэй и М.Дж. Кейн реализовали ряд экспериментов:

- измерения при «уходе в свои мысли» при выполнении заданий, требующих концентрации и внимания,

- измерение результативности выполнения таких задач,

- прогнозирование способности осмысления прочитанного текста через внимание.

По итогу проведения исследований авторы зафиксировали, что участники с более низкими оценками понимания прочитанного были более склонны к «уходу в свои мысли», и наоборот.

Исследователь П.Ф. Делани сосредотачивает внимание на других экспериментах, которые соприкасаются с изучением характеристик памяти в состоянии «ухода в свои мысли»:

- в одном эксперименте участникам необходимо было запомнить предложенные слова, далее представить/помечтать о своем или родительском доме. После этого испытуемым представили еще один список слов для запоминания,

- во втором исследовании участникам также изначально необходимо было запомнить первый перечень слов, после чего помечтать об отпуске или каникулах, проведенных в других странах и дома. Далее были также предложены слова из второго списка для запоминания.

И в первом, и во втором экспериментах участники, которые представляли далеких места (родители и отпуск в других странах) зафиксировали в своей памяти меньше слов из первоначального перечня, чем после размышлений о текущей ситуации (дом и отдых дома). При этом две группы не продемонстрировали различия в запоминании слов из списка №2. Учитывая результаты экспериментов, П.Ф. Делани пришел к выводу, что мечтание о далеких временах или местах добавляет еще один негативный эффект - забывание событий, произошедших как раз перед «уходом в свои мысли».

Мэтью А. Киллингсворс и Дэниел Т. Гилберт выдвинули еще одну идею негативном влиянии «ухода в свои мысли». Исследование заключалось в том, что случайные пользователи фиксировали ответы на вопросы относительно настроения, чувств, ощущений во время данного феномена в новом приложении на iPhone. Указанный эксперимент был очень масштабным: 5000 участников из 83 стран, возрастная группа от 18 до 88 лет. Авторы отметили, что состояние «ухода в свои мысли» явление очень частое. Участники эксперимента поделились наблюдением, что они менее счастливы, находясь в этом состоянии, а также, указанное состояние у многих выступало предвестником несчастий. В итоге, исследователи и группа испытуемых сделали вывод, что феномен «ухода в свои мысли» зачастую является причиной несчастья потому, что само пребывание в этом состоянии - несчастно». Данные выводы продемонстрировали, что «уход в свои мысли» - это достаточно негативное явление, которое сводит к нулю любые положительные решения проблем. Киллингсворс и Гилберт, совместно с Бэйрдом, полагали, что творческие люди, например, художники, более несчастны.

Исследования Бенджамина Бэйрда, напротив, демонстрируют позитивную сторону изучаемого понятия, в частности о творческом методе решения проблем. Автор высказал мнение, что «уход в свои мысли» не является следствием решения трудных задач. Выводы Бэрда говорят о том «уход в себя» оказывает ключевое влияние на творческий процесс, творчество существует только в такой среде, где человек не размышляет о непосредственной проблеме.

Исследователи также выделяют и другие плюсы рассматриваемого феномена. «Уход в свои мысли» говорит о емкости рабочей памяти, то есть способность думать 
одновременно о двух и более событиях, это подтверждается рядом экспериментов. Участники, которые «уходили в себя» чаще, демонстрировали самый большой объем рабочей памяти. Дж. Смоллвуд пояснил, что люди зачастую в повседневных делах поддерживают эти процессы рабочей памятью. При этом их мозг старается выделять ресурсы на решение наиболее актуальных проблем.

«Уход в свои мысли» также помогает нам формировать воспоминания. Нейробиолог Ариэль Тамбини провела исследование, которое заключалось в следующем. Людям необходимо было смотреть на пары изображений, а в перерывах они размышляли/мечтали, о чем угодно. С помощью МРТ исследователи наблюдали за деятельностью в области коры. Установлено, что мозг работает на человека, когда он отдыхает, так что отдых очень необходим для памяти и когнитивных функций.

Учитывая вышеизложенное, состояние «ухода в свои мысли» несет в себе как положительные, так и отрицательные моменты. Ряд исследований это наглядно доказывают. Для творческих личностей, действительно, «уход в свои мысли» чрезвычайно важен. Данный феномен также важен для отдыха мозга: в этот момент информация структурируется, фиксируется в памяти на длительную перспективу. Разумеется, во время пребывания в мечтах люди теряют внимательность, поэтому при решении сложных задач, где требуется максимум сосредоточенности эпизоды «ухода в свои мысли» необходимо исключить.

\section{Зак^ючение}

На сегодняшний день уделяется недостаточно внимания изучению процесса перехода от восприятия внешней информации к внутренним процессам. Самоосознание личности строится на консолидации:

- знаний о себе в настоящем

- воспоминаний себя в прошлом

- прогнозов событий, которые произойдут в будущем
Таким образом, запускается механизм сравнения опыта, который происходит «здесь и сейчас», с мотивами и ожиданиями личности. Понятие «ухода в свои мысли» противоречиво, имеет неоднозначные трактовки. Данный феномен в противовес рефлексии и метапознанию является своего рода нарушением саморегуляции, отвлечением от выполнения задачи. Главная сложность, возникающая во время исследования «ухода в свои мысли», состоит в том, что возможно фиксировать предмет наличия этого состояния, но не момент его возникновения, а также его длительность. Такие способы исследования как самоотчеты испытуемых, поведенческие данные и информация по нейровизуализации позволяют изучить феномен «ухода в свои мысли» более детально. В этой связи особый интерес представляет исследование работы «дефолтной» сети мозга.

Отношение к мечтательности, которая является частью психической жизни, различное, в зависимости от культуры и времени. 3. Фрейд, например, называл мечтателей инфантильными невротиками. Восточные практики направлены на полную концентрацию человека.

На сегодняшний день исследования сходятся во мнении, что «уход в свои мысли» в ежедневной деятельности - широко распространенное состояние. При выполнении текущей деятельности оно может быть причиной допущения ошибок из-за невнимательности, поэтому и несет угрозу во многих видах профессиональной деятельности. Но, с другой стороны, именно «уход в свои мысли» выступает в роли полезного инструмента в долгосрочной перспективе, запускает оценку опыта из прошлого, планирование новой деятельности и инкубацию творческих решений. Объединяет различные взгляды на понятие «ухода в свои мысли» высокий уровень личностной значимости, которая задействует механизмы перераспределения когнитивных ресурсов. Значение когнитивного контроля в инициации и остановке эпизодов «ухода в свои мысли» требует дальнейшего изучения.

\section{ЛИТЕРАТУРА}

1. Гальперин, П.Я. К проблеме внимания. - М.: Институт практической психологии, 1982.- 169 с.

2. Зинченко, В.П. Опыт думания о думании. К восьмидесятилетию В.В. Давыдова (1930-1998)//Вопросы философии, 2010, 75-91с.

3. Леонтьев, Д.А., Осин, Е.Н. Рефлексия «хорошая» и «дурная»: от объяснительной модели к дифференциальной диагностике // Психология. Журнал Высшей школы экономики, 2014, 110-135 с.

4. Шадриков, В.Д.. Ментальное развитие человека. - М.: Аспект Пресс, $2004-29$ с.

5. Шадриков, В.Д. Мысль и познание. - М.: Логос, 2014, 53 с.

6. Baird, B., Smallwood, J., Mrazek, M.D., Kam, J.W.Y., Franklin, M.S., \& Schooler, J.W. Inspired by distraction: mind wandering facilitates creative incubation.// Psychological Science, 2014, 1117-1122p.

7. Killingsworth, M.A., \& Gilbert, D.T. (2010) A wandering mind is an unhappy mind. Science, 330,932. doi:org/10.1126/science.1192439

8. Knyazev, G.G., Savostyanov, A.N., Volf, N.V., Liou, M., \& Bocharov, A. V. (2012). EEG correlates of spontaneous self-referential thoughts: A cross-cultural study. 
International Journal of Psychophysiology, 86, 173-181. doi:org/10.1016/j.jppsycho.2012.09.002

9. McMillan, R.L., Kaufman, S.B., \& Singer, J.L. (2013). Ode to positive constructive daydreaming. Frontiers in Psychology, 4, 626. doi:org/10.3389/fpsyg.2013.00626

10. McVay, J.C., \& Kane, M.J. (2010). Does mind wandering reflect executive function or executive failure? Comment on Smallwood and Schooler (2006) and Watkins (2008). Psychological Bulletin, 136, 188-197. doi:org/10.1037/a0018298

(c) Матвеева Евгения Юрьевна (epoteruha@mail.ru).

Журнал «Современная наука: актуальные проблемы теории и практики»

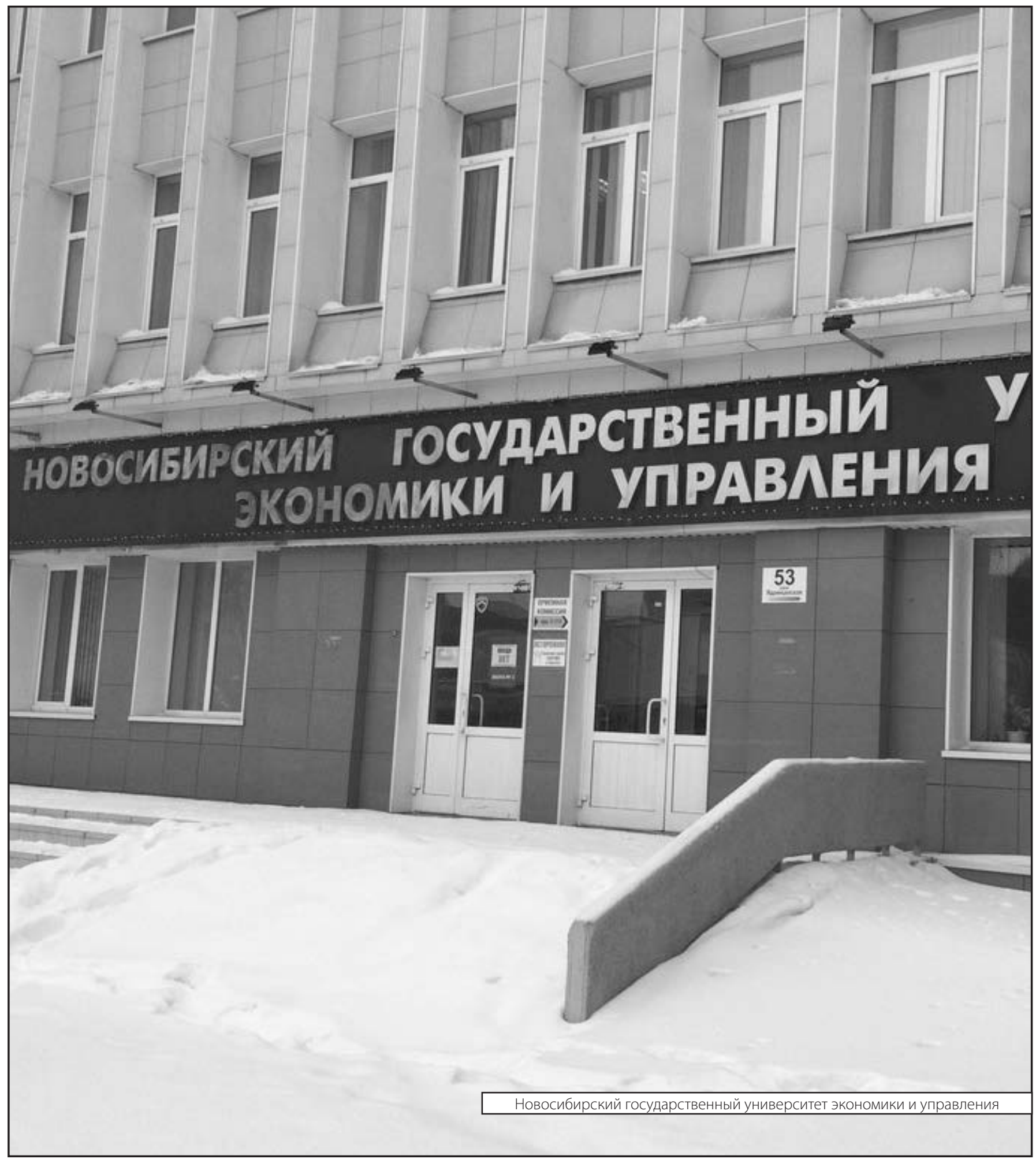

